\title{
Mid Regional Natriuretic Peptide for Predicting Prognosis of Hypertrophic Cardiomyopathy
}

\author{
Niranjan Reddy R ${ }^{\odot}$, Magesh B $\odot$ \\ Assistant Professor, Department of Cardiology, Sapthagiri Institute of Medical Sciences and Research Centre, Bangalore, Karnataka, India.
}

\section{Abstract}

Background: Hypertrophic cardiomyopathy (HCM) is a genetic disorder of cardiac myocytes that is characterized by cardiac hypertrophy, cellular disarray and interstitial fibrosis. Mutation of MYH7 and MYBPC3 encoding proteins $\beta$-myosin heavy chain and myosin binding protein C, respectively, are the two most common genes involved, together accounting for about $50 \%$ of cases. The present study was conducted to evaluate the prognostic value of MR-proANP in patients with HCM. Subjects and Methods: The present study was conducted at Narayana Medical College \& Hospital, Chintareddy Palem, Nellore, Andhra Pradesh from July 2016 to July 2017 on 46 patients of hypertrophic cardiomyopathy of both genders. Serum NT-proBNP was measured by a two-site electrochemiluminescence immunoassay on a Roche Diagnostics E170 analyser. Results: The mean systolic blood pressure was $124.8 \mathrm{~mm} \mathrm{Hg}$, diastolic blood pressure was $78 \mathrm{~mm} \mathrm{Hg}$, heart rate was 68 beats/minutes, NYHA $1(n=4)$, NYHA 2 ( $n=27)$, NYHA 3-4 $(n=15)$ and atrial fibrillation was $12 \%$. The mean MR-proANP was 106 pmol/L and NT-proBNP was 540 $\mathrm{pg} / \mathrm{mL}$ at the start of the study. At the end of 12 months of follow up, 15 patients had a primary end point defined as heart failure hospitalisation $(n=10)$, heart transplant $(n=3)$ death $(n=2)$. Both mean MR-proANP and NT-proBNP were strongly associated with the primary end points at the end of study period with values of $1010 \mathrm{pmol} / \mathrm{L}$ and $2545 \mathrm{pg} / \mathrm{ml}$ respectively. This showed a strong association with $\mathrm{P}<0.05$. Conclusion: Authors found that MR-proANP is a valuable biomarker for the prediction of heart failure related events in patients with HCM.

Keywords: Heart Failure, Hypertrophic Cardiomyopathy, Immunoassay

Corresponding Author: Magesh B, Assistant Professor, Department of Cardiology, Sapthagiri Institute of Medical Sciences and Research Centre, Bangalore, Karnataka, India.

E-mail: drbmagesh@gmail.com

Received: 21 January 2020

Revised: 8 March 2020

Accepted: 17 March 2020

Published: 18 May 2020

\section{Introduction}

Hypertrophic cardiomyopathy (HCM) is a genetic disorder of cardiac myocytes that is characterized by cardiac hypertrophy, unexplained by the loading conditions; a nondilated left ventricle; and a normal or increased ejection fraction. ${ }^{[1]}$ Cardiac hypertrophy is usually asymmetrical with greatest involvement most commonly of the basal interventricular septum subjacent to the aortic valve. It is occasionally restricted to other myocardial regions, such as the apex, the midportion and the posterior wall of the left ventricle. At the cellular level, cardiac myocytes are hypertrophied, disorganized, and separated by areas of interstitial fibrosis. HCM is a disorder without a distinct geographic, ethnic or sex pattern of distribution. Prevalence of HCM has been estimated at $0.16 \%$ to $0.29 \%$ in the general adult population. ${ }^{[2]}$ In adults, HCM may be diagnosed by the presence of left ventricular end diastolic wall thickness $>13 \mathrm{~mm}$ on an echocardiogram or other imaging technique. The European Society of Cardiology guidelines recommend using a left ventricular wall thickness of $\geq 15 \mathrm{~mm}$ in the diagnostic criteria. ${ }^{[3]}$ Estimating the prevalence of HCM based on detection of cardiac hypertrophy, although clinically valuable, has many limitations. ${ }^{[4]}$

Natriuretic peptides are released from the heart due to increased myocardial wall stretch caused by volume and pressure overload. Mid-regional proatrial natriuretic peptide (MR-proANP) is the mid-regional epitope of the ANP prohormone which, like NT-proBNP, has a long circulating half-life. ${ }^{[5]}$ MR-proANP may be equal or superior to BNP or NT-proBNP for diagnosis and prognosis in heart failure (HF). The present study was conducted to evaluate the prognostic value of MR-proANP in patients with HCM.

\section{Subjects and Methods}

The present study was conducted at Narayana Medical College \& Hospital, ChintareddyPalem, Nellore, Andhra Pradesh from July 2016 to July 2017 on 46 patients of 
hypertrophic cardiomyopathy of both genders. The patients were informed regarding the study and written consent was taken. Institutional Ethical approval was obtained from committee before starting the study.

Left ventricular hypertrophy was assessed with echocardiography according to published criteria. ${ }^{[4]}$ Left ventricular end diastolic and end systolic diameters and left atrial diameters were obtained from M-Mode and two-dimensional images from the parasternal view. LVEF was calculated according to Simpson biplane method. Septal and posterior wall thicknesses were measured from the parasternal view.

Venous blood samples were collected. Samples were immediately centrifuged. Supernatant serum was stored at $-80^{\circ} \mathrm{C}$ until the samples were analysed. Serum NT-proBNP was measured by a two-site electrochemiluminescence immunoassay on a Roche Diagnostics E170 analyser. Results were subjected to statistical analysis. $\mathrm{P}$ value less than 0.05 was considered significant.

\section{Results}

\section{Table 1: Distribution of patients}

\begin{tabular}{|lll|}
\hline Total- 46 & & \\
\hline Gender & Males & Females \\
\hline Number & 26 & 20 \\
\hline
\end{tabular}

Table 1 shows that out of 46 patients, males were 26 and females were 20.

Table 2: Assessment of parameters

\begin{tabular}{|l|l|}
\hline Parameters & Mean \\
\hline Systolic blood pressure & $124.8 \mathrm{~mm} \mathrm{Hg}$ \\
\hline Diastolic blood pressure & $78 \mathrm{~mm} \mathrm{Hg}$ \\
\hline Heart rate & 68 beats/min \\
\hline & \\
\hline NYHA 1 & 4 \\
\hline NYHA 2 & 27 \\
\hline NYHA 3-4 & 15 \\
\hline Atrial fibrillation & $12 \%$ \\
\hline
\end{tabular}

Table 2 shows that mean systolic blood pressure was $124.8 \mathrm{~mm}$ $\mathrm{Hg}$, diastolic blood pressure was $78 \mathrm{~mm} \mathrm{Hg}$, heart rate was 68 beats/minutes, NYHA-1 was 4, NYHA-2 was 27, NYHA 3-4 was 15 and atrial fibrillation was $12 \%$.

Table 3 shows that mean MR-proANP was $106 \mathrm{pmol} / \mathrm{L}$ and NT-proBNP was $540 \mathrm{pg} / \mathrm{mL}, \mathrm{LV}$ end diastolic dimension was $46 \mathrm{~mm}, \mathrm{LV}$ ejection fraction was $62 \%$, LV ejection fraction $<50 \%$ was 40 , posterior wall thickness was $12 \mathrm{~mm}$, septal wall

\begin{tabular}{|c|c|}
\hline Variables & Mean \\
\hline MR-proANP (pmol/L) & 106 \\
\hline NT-proBNP (pg/mL) & 540 \\
\hline \multicolumn{2}{|l|}{ Echocardiography data } \\
\hline LV end diastolic dimension & $46 \mathrm{~mm}$ \\
\hline LV ejection fraction & $62 \%$ \\
\hline LV ejection fraction $<50 \%$ & 40 \\
\hline Posterior wall thickness & $12 \mathrm{~mm}$ \\
\hline Septal wall thickness & $19 \mathrm{~mm}$ \\
\hline Maximum wall thickness & $20 \mathrm{~mm}$ \\
\hline Left atrial diameter & $42 \mathrm{~mm}$ \\
\hline
\end{tabular}

thickness was $19 \mathrm{~mm}$, maximum wall thickness was $20 \mathrm{~mm}$ and left atrial diameter was $42 \mathrm{~mm}$.

\begin{tabular}{llll|}
\hline Table 4: Marker values & & \\
\hline Markers (mean) & $\begin{array}{l}\text { Start of study } \\
(\mathbf{n}=\mathbf{4 6})\end{array}$ & $\begin{array}{l}\text { End } \\
\text { study(end } \\
\text { point achievers } \\
\mathbf{n = 1 5}) .\end{array}$ \\
\hline $\begin{array}{l}\text { NT-proBNP } \\
(\mathrm{pg} / \mathrm{mL})\end{array}$ & 540 & $2545^{*}$ \\
\hline $\begin{array}{l}\mathrm{MR}-\mathrm{proANP} \\
(\mathrm{pmol} / \mathrm{L})\end{array}$ & 106 & $1010^{*}$ \\
\hline${ }^{* \mathrm{P}<0.05}$ & & \\
\hline
\end{tabular}

Table 4 shows the statistically significant increase in mean values of both NT-proBNP and MR-proANP of those who achieved primary end point.

\section{Discussion}

Hypertrophic cardiomyopathy (HCM) is a genetic disorder that is characterized by left ventricular hypertrophy unexplained by secondary causes and a nondilated left ventricle with preserved or increased ejection fraction. It is commonly asymmetrical with the most severe hypertrophy involving the basal interventricular septum. Left ventricular outflow tract obstruction is present at rest in about one third of the patients and can be provoked in another third. ${ }^{[6]}$ The histological features of HCM include myocyte hypertrophy and disarray, as well as interstitial fibrosis. The hypertrophy is also frequently associated with left ventricular diastolic dysfunction. In the majority of patients, HCM has a relatively benign course. However, HCM is also an important cause of sudden cardiac death, particularly in adolescents and young adults. The diagnostic and prognostic values of brain natriuretic peptide (BNP) and N-terminal proBNP (NT-proBNP) are now well- 
established in heart failure. In HCM, increased BNP and NTproBNP concentrations have been associated with evidence of ventricular dysfunction, exercise intolerance, the development of heart failure and death. ${ }^{[7]}$ The present study was conducted to evaluate the prognostic value of MR-proANP in patients with HCM.

In present study, out of 46 patients, males were 26 and females were 20 . Begue et $\mathrm{al}^{\left[{ }^{[8]}\right.}$ compared the prognostic value of MR-proANP and NT-proBNP in HCM. Of 357 patients enrolled, the median age was 52 years. MR-proANP and NT-proBNP were both independently associated with age, weight, New York Heart Association (NYHA) class, left ventricular ejection fraction (LVEF), wall thickness and left atrial dimension. During a median follow-up of 12 months, 15 patients had a primary end point defined as death $(n=2)$, heart transplantation $(\mathrm{n}=3)$, and heart failure hospitalisation $(\mathrm{n}=10)$. Both NT-proBNP and MR-proANP $(\mathrm{p}<10-4)$ were strongly associated with the primary endpoint, and the areas under the receiver operating characteristic (ROC) curves for both peptides were not significantly different. However, in a multiple stepwise regression analysis, the best model for predicting outcome was NYHA $1-2$ vs 3-4, LVEF and MRproANP.

We found that mean systolic blood pressure was $124.8 \mathrm{~mm}$ $\mathrm{Hg}$, diastolic blood pressure was $78 \mathrm{~mm} \mathrm{Hg}$, heart rate was 68 beats/minutes, NYHA 1was 136, NYHA 2 was 148 , NYHA 3-4 was 38 and atrial fibrillation was $12 \%$. The mean MRproANP was $106 \mathrm{pmol} / \mathrm{L}$, NT-proBNP was $540 \mathrm{pg} / \mathrm{mL}$, LV end diastolic dimension was $46 \mathrm{~mm}, \mathrm{LV}$ ejection fraction was $62 \%$, LV ejection fraction $<50 \%$ was 40 , posterior wall thickness was $12 \mathrm{~mm}$, septal wall thickness was $19 \mathrm{~mm}$, maximum wall thickness was $20 \mathrm{~mm}$ and left atrial diameter was $42 \mathrm{~mm}$.

Briguori et al, ${ }^{[9]}$ reported that plasma concentration of ANP in $\mathrm{HCM}$ was strongly associated with left atrial function, whereas BNP was strongly associated with obstruction. Only one study, including only 40 patients, has investigated MR-proANP in patients with HCM, showing that among several biomarkers, MR-proANP was the only one associated with the extent of late gadolinium enhancement on MRI.

Geske et al, ${ }^{[10]}$ reported increased plasma concentrations of BNP and NT-proBNP in patients with HCM and shown that they are associated with more left ventricular hypertrophy, more left ventricular outflow tract obstruction, left ventricular diastolic and systolic dysfunction, worse symptoms and reduced exercise tolerance. This is not unexpected, as the main source of BNP is cardiomyocytes and increased ventricular wall stress the major stimulus to its secretion.

\section{Conclusion}

Authors found that MR-proANP is a valuable biomarker for the prediction of heart failure related events in patients with HCM.

\section{References}

1. Maron BJ, Maron MS. Hypertrophic cardiomyopathy. Lancet. 2013;381(9862):242-255. Available from: https://dx.doi.org/ 10.1016/s0140-6736(12)60397-3.

2. Elliott PM, Anastasakis A, Borger MA. ESC Guidelines on diagnosis and management of hypertrophic cardiomyopathy: The Task Force for the Diagnosis and Management of Hypertrophic Cardiomyopathy of the European Society of Cardiology (ESC). Eur Heart J. 2014;2014:2733-79. Available from: https://dx.doi.org/10.1093/eurheartj/ehu284.

3. Volpe M, Rubattu S, Burnett J. Natriuretic peptides in cardiovascular diseases: current use and perspectives. Eur Heart J. 2014;35(7):419-425. Available from: https://dx.doi.org/10. 1093/eurheartj/eht466.

4. Yang H, Woo A, Monakier D, Jamorski M, Fedwick K, Wigle ED, et al. Enlarged Left Atrial Volume in Hypertrophic Cardiomyopathy: A Marker for Disease Severity. J Am Soc Echocardiogr. 2005;18(10):1074-1082. Available from: https: //dx.doi.org/10.1016/j.echo.2005.06.011.

5. Epstein FH, Levin ER, Gardner DG, Samson WK. Natriuretic Peptides. N Eng J Med. 1998;339(5):321-328. Available from: https://dx.doi.org/10.1056/nejm199807303390507.

6. Maisel AS, Krishnaswamy P, Nowak RM. Breathing not properly multinational study investigators. Rapid measurement of B-type natriuretic peptide in the emergency diagnosis of heart failure. N Engl J Med. 2002;347:161-168. Available from: https://dx.doi.org/10.1056/NEJMoa020233.

7. Isnard R, Pousset F, Chafirovskaïa O, Carayon A, Hulot JS, Thomas D, et al. Combination of B-type natriuretic peptide and peak oxygen consumption improves risk stratification in outpatients with chronic heart failure. Am Heart J. 2003;146(4):729-735. Available from: https://dx.doi.org/10. 1016/s0002-8703(03)00365-x.

8. Bégué C, Mörner S, Brito D, Hengstenberg C, Cleland JGF, Arbustini E, et al. Mid-regional proatrial natriuretic peptide for predicting prognosis in hypertrophic cardiomyopathy. Heart. 2019;106(3):196-202. Available from: https://dx.doi.org/10. 1136/heartjnl-2019-314826.

9. Briguori C. Determinants and clinical significance of natriuretic peptides and hypertrophic cardiomyopathy. Eur Heart J. 2001;22(15):1328-1336. Available from: https://dx.doi.org/10. 1053/euhj.2000.2535.

10. Geske JB, McKie PM, Ommen SR, Sorajja P. B-Type Natriuretic Peptide and Survival in Hypertrophic Cardiomyopathy. J Am Coll Cardiol. 2013;61(24):2456-2460. Available from: https://dx.doi.org/10.1016/j.jacc.2013.04.004. 
Copyright: (C) the author(s), 2020. It is an open-access article distributed under the terms of the Creative Commons Attribution License (CC BY 4.0), which permits authors to retain ownership of the copyright for their content, and allow anyone to download, reuse, reprint, modify, distribute and/or copy the content as long as the original authors and source are cited.

How to cite this article: Reddy R N, Magesh B . Mid Regional Natriuretic Peptide for Predicting Prognosis of Hypertrophic Cardiomyopathy. Acad. J Med. 2020;3(1):15-18.

DOI: dx.doi.org/10.47008/ajm.2020.3.1.4

Source of Support: Nil, Conflict of Interest: None declared. 